\title{
COVID-19 pandemic: a wake-up call for lifestyle-related preventable conditions in older adults
}

\author{
Michael Anthonius Lim ${ }^{1}$ (D) Lee Smith ${ }^{2}$
}

Received: 1 June 2021 / Accepted: 13 June 2021 / Published online: 21 June 2021

(c) The Author(s), under exclusive licence to Springer Nature Switzerland AG 2021

The coronavirus disease 2019 (COVID-19) pandemic has dominated nearly every aspect of the world for more than a year. Medical services have been affected significantly, with prioritization of COVID-19 patients and delays in elective cases leaving vulnerable population at increased risk of developing non-communicable diseases or worsening of their pre-existing illnesses [1]. Hypertension, diabetes, and cardiovascular and cerebrovascular diseases are the most prevalent conditions associated with increased severity and mortality in COVID-19 patients, as well as advancing age, excessive body mass index (BMI), frailty, and various other chronic conditions. The elderly population in particular is likely to worsen their underlying debilitating conditions during the ongoing pandemic, making them more prone to both infectious and non-communicable conditions [2]. Considering the susceptibility of these individuals, routine follow-up and modification of current treatment might be interrupted or even postponed indefinitely during the current pandemic, increasing the burden of already overwhelmed medical workers.

Long before the coronavirus disease 2019 (COVID-19) outbreak, physical inactivity was considered a global pandemic that was often underestimated or even ignored by communities and public health authorities [3]. During the current long-lasting pandemic, people continue to move less for various reasons bringing the trends of physical inactivity and sedentarism to new heights. The lack of physical activity is the fourth leading cause of mortality worldwide, a significant contributor for poor physical and mental health

Michael Anthonius Lim

lim.michael.a@gmail.com

Lee Smith

lee.smith@aru.ac.uk

1 Faculty of Medicine, Universitas Pelita Harapan, Tangerang, Indonesia

2 The Cambridge Centre for Sport and Exercise Sciences, Anglia Ruskin University, Cambridge, UK outcomes, as well as a huge social and economic burden on the population and government. Likewise, sedentary behaviours carry similar consequences which require the simultaneous attention of public health efforts [4]. To date, public health authorities have focused on limiting the spread of transmission through widely applied mitigation approaches, including lockdowns, travel bans, isolation, quarantine, social distancing, personal protective measures as well as hygiene measures such as environmental and surface cleaning, while forgetting to emphasize the importance of engaging a physically active lifestyle [5]. Obesity prevention and physical activity promotion are at least as important as the extensively implemented restrictions during the current pandemic.

Both physical inactivity and sedentary behaviours have been consistently associated with greater risks of adverse health outcomes $[6,7]$. Although these two entities are closely related, they have different meanings. Physical activity refers to any bodily movement (characterized by its modality, frequency, intensity, duration and context of practice) produced by the contraction of skeletal muscles which increases energy expenditure beyond the resting metabolic rate. In terms of physical inactivity, it can be defined when someone does not fulfil the criteria or guideline of physical activity. Meanwhile, sedentary behaviours refer to any waking behaviours identified by an energy expenditure of $\leq 1.5$ METs (metabolic equivalent of tasks), while in a sitting, reclining, or lying posture [8]. These adverse and unhealthy lifestyles, along with unfavourable dietary habits, clearly elevate the risk of being overweight and obese, having poor cardiometabolic health and fitness developing non-communicable conditions as well as contracting various infectious diseases [9, 10].

With regard to the COVID-19 severity and mortality, a higher risk of hospitalization, ICU admission, and death has been observed in physically inactive individuals compared to those engaging in a variety of physical activity [11]. Behind the severe course of COVID-19, there is hyperinflammation 
due to chronic, systemic, low-grade inflammation driven by comorbidities. Inadequate physical activity is known to be an independent risk factor for a range of chronic, lifestylerelated, preventable conditions (e.g. obesity, diabetes mellitus type 2, hypertension, dyslipidemia, cardiovascular and cerebrovascular diseases) which are among the comorbidities associated with severe COVID-19 infection [9, 12]. Meeting physical activity requirements has been advocated by the World Health Organization (WHO) to gain health benefits and mitigate health risks, but this has not been met by the vast majority of people.

In today's digitalisation era where the majority of people work, study, socialize, or even spend their leisure time virtually, exacerbated by the COVID-19 containment, trends in physical inactivity and sedentary behaviour will worsen [4]. In society, the elderly population is at high risk of developing severe COVID-19, taking into account advancing age and the presence of comorbidities. Such high-risk individuals are largely confined by COVID-19 restrictions, urged to stay at home and even postpone their routine medical follow-ups or elective procedures, thus limiting their mobility and consequently inducing sedentariness. Hence, in the near future, the wave of non-communicable diseases and frailty conditions (e.g. osteoporosis, sarcopenia) may appear inevitable without appropriate intervention of public health authorities around the world $[1,2]$. This is a wake-up call to create a more sustainable approach to help individuals, especially older people, practicing physically active lifestyle. We advocate that physical activity now more than ever must receive special attention from the governments and health authorities and should be prescribed by health professional to prevent and treat a wide variety of physical and mental health problems, especially in the elderly population [13].

Authors' contributions MAL and LS confirm being the only contributors of this work and have approved it for publication.

Funding None.

\section{Declarations}

Conflict of interest The authors declare that they possess no commercial or financial relationships that could be construed as a potential conflict of interest.

Ethical approval Not required.

Informed consent Not required.

\section{References}

1. Lim MA, Huang I, Yonas E et al (2020) A wave of non-communicable diseases following the COVID-19 pandemic. Diabetes Metab Syndr Clin Res Rev 14:979-980. https://doi.org/10.1016/j. dsx.2020.06.050

2. Lim MA, Kurniawan AA (2021) Dreadful consequences of sarcopenia and osteoporosis due to COVID-19 containment. Geriatr Orthop Surg Rehabil. https://doi.org/10.1177/2151459321992746

3. Kohl HW 3rd, Craig CL, Lambert EV et al (2012) The pandemic of physical inactivity: global action for public health. Lancet (London, England) 380:294-305. https://doi.org/10.1016/S01406736(12)60898-8

4. Hall G, Laddu DR, Phillips SA et al (2021) A tale of two pandemics: how will COVID-19 and global trends in physical inactivity and sedentary behavior affect one another? Prog Cardiovasc Dis 64:108-110. https://doi.org/10.1016/j.pcad.2020.04.005

5. Lim MA, Pranata R (2020) Sports activities during any pandemic lockdown. Ir J Med Sci. https://doi.org/10.1007/ s11845-020-02300-9

6. Cunningham C, O'Sullivan R, Caserotti P et al (2020) Consequences of physical inactivity in older adults: a systematic review of reviews and meta-analyses. Scand J Med Sci Sports 30:816827. https://doi.org/10.1111/sms.13616

7. de Rezende LFM, Lopes MR, Rey-López JP et al (2014) Sedentary behavior and health outcomes: an overview of systematic reviews. PLoS ONE 9:e105620. https://doi.org/10.1371/journal. pone. 0105620

8. Thivel D, Tremblay A, Genin PM et al (2018) Physical activity, inactivity, and sedentary behaviors: definitions and implications in occupational health. Front Public Health 6:288. https://doi.org/ 10.3389/fpubh.2018.00288

9. Lee I-M, Shiroma EJ, Lobelo F et al (2012) Effect of physical inactivity on major non-communicable diseases worldwide: an analysis of burden of disease and life expectancy. Lancet (London, England) 380:219-229. https://doi.org/10.1016/S0140-6736(12) 61031-9

10 Chastin SFM, Abaraogu U, Bourgois JG et al (2021) Effects of regular physical activity on the immune system, vaccination and risk of community-acquired infectious disease in the general population: systematic review and meta-analysis. Sport Med. https:// doi.org/10.1007/s40279-021-01466-1

11 Sallis R, Young DR, Tartof SY et al (2021) Physical inactivity is associated with a higher risk for severe COVID-19 outcomes: a study in 48,440 adult patients. Br J Sports Med. https://doi.org/ 10.1136/bjsports-2021-104080

12. Lim MA, Pranata R, Huang I et al (2020) Multiorgan failure with emphasis on acute kidney injury and severity of COVID19: systematic review and meta-analysis. Can J Kidney Heal Dis 7:2054358120938573. https://doi.org/10.1177/2054358120 938573

13. Roberts CE, Phillips LH, Cooper CL et al (2017) Effect of different types of physical activity on activities of daily living in older adults: systematic review and meta-analysis. J Aging Phys Act 25:653-670. https://doi.org/10.1123/japa.2016-0201

Publisher's Note Springer Nature remains neutral with regard to jurisdictional claims in published maps and institutional affiliations. 